\title{
Midazolam oral solution (Ozalin ): a profile of its use for procedural sedation or premedication before anaesthesia in children
}

\author{
Katherine A. Lyseng-Williamson ${ }^{1}$ (1)
}

Published online: 16 April 2019

๑) Springer Nature 2019, corrected publication 2019

\begin{abstract}
Ozalin $^{\circledR}$, a novel oral solution of $0.2 \%$ midazolam, is an effective option for moderate sedation prior to a therapeutic or diagnostic procedure, and as premedication before anaesthesia, in infants, children and adolescents. Orally administered midazolam has a rapid onset and short duration of action, with well-established favourable efficacy, tolerability, safety and acceptability profiles in these indications. To overcome the problems of bitter taste and inconsistent bioavailability associated with extemporaneous formulations of oral midazolam, Ozalin, a commercially prepared oral midazolam formulation, contains the inert excipient $\gamma$-cyclodextrin, which forms inclusion complexes with midazolam, thereby enhancing the solubility and stability of midazolam solutions, and masking its bitter taste. Ozalin is administered at the lowest dose of midazolam (i.e. $0.25 \mathrm{mg} / \mathrm{kg}$ ) that has been shown to be effective, with this dose providing sedative effects consistent with the historical data for midazolam at doses that were the same or higher (i.e. $0.5-1.5 \mathrm{mg} / \mathrm{kg}$ ).
\end{abstract}

Adis evaluation of Ozalin for procedural sedation

or premedication before anaesthesia in paediatric patients (aged 6 months to 17 years)

Oral midazolam has well-established benefits as a noninvasive procedural sedative or a premedication before anaesthesia, and is well accepted by paediatric patients and caregivers

Novel oral formulation containing $\gamma$-cyclodextrin provides consistent exposure to midazolam, is pharmacologically stable and masks the bitter taste of midazolam

Dose is based on actual bodyweight, regardless of the age of the child, as bodyweight affects exposure to midazolam

Fixed-dose of $0.25 \mathrm{mg} / \mathrm{kg}$ is as effective as higher doses (i.e. $0.5-1.5 \mathrm{mg} / \mathrm{kg}$ ) in providing sedation

Oral applicator is graduated by bodyweight, reducing the potential for errors in converting bodyweight-based doses to $\mathrm{mg} / \mathrm{mL}$

Katherine A. Lyseng-Williamson

dtp@adis.com

1 Springer, Private Bag 65901, Mairangi Bay, Auckland 0754, New Zealand

\section{What is the rationale for developing a novel oral solution of midazolam?}

Midazolam is very commonly used to provide procedural sedation or premedication before anaesthesia in infants, children and adolescents, due to its sedative properties and its rapid onset and short duration of action [1-4]. Oral formulations of midazolam are easy to administer, are effective in providing sedation, have minimal effects on recovery times and time to discharge, and are well tolerated, as shown in numerous studies of extemporaneous and marketed oral midazolam solutions/syrups in paediatric patients requiring procedural sedation or premedication before anaesthesia [5-14]. The use of oral midazolam as a premedication may be preferred over the use of midazolam administered by intravenous (IV) injection [10, 11], rectal suppository [12] or intranasal spray $[13,14]$.

Prior to the development of commercially prepared oral formulations of midazolam, extemporaneous solutions of midazolam were prepared from injectable solutions of the drug [2]. Various syrups, solutions and drinks have been mixed with injectable midazolam in order to try to mask the strong bitter taste of midazolam and improve its palatability [15-17]. However, the taste of such extemporaneous preparations may still not be acceptable to paediatric patients, and their stability is relatively short, being limited to a few weeks or months $[15,16]$. 
Moreover, midazolam, a weak acid, is weakly soluble in water [2]. In aqueous solutions, midazolam is present as a more soluble 'ring-open' form and a lipophilic 'ring-closed' form, the ratio of which is $\mathrm{pH}$ dependent $[2,18]$. The specific drink or liquid added as flavouring may change the $\mathrm{pH}$ of the solution and the solubility of midazolam [17]. In turn, this may affect the bioavailability and pharmacokinetic profile of midazolam and, ultimately, lead to unpredictable clinical responses [17].

In response to the need for palatable oral formulations of midazolam with consistent bioavailability and pharmacological properties, commercially prepared formulations of oral midazolam have been developed. One such formulation is Ozalin ${ }^{\circledR}[1]$, an oral solution of $0.2 \%$ midazolam containing $\gamma$-cyclodextrin (hereafter referred to Ozalin to distinguish it from other oral midazolam solutions).

\section{How is Ozalin formulated?}

Ozalin is formulated by adding $\gamma$-cyclodextrin to a citric acid solution of midazolam [2]. Citric acid, an acid buffer, is used to improve the solubility of weak hydrophobic acids, such as midazolam, in aqueous solutions $[2,17]$. $\gamma$-Cyclodextrin, which forms inclusion complexes with weak acids, is used to further improve the solubility of the weak acid and enhance the stability of such solutions $[2,19,20]$. The use of $\gamma$-cyclodextrin in the citric acid solution of midazolam results in the formation of $\gamma$-cyclodextrin-midazolam inclusion complexes, which enhance the stability and solubility of midazolam in the citric acid solution, and mask the bitter taste of midazolam [2,20]. Ozalin also contains sucralose (a sweetener) and orange flavour [1] to further enhance its palatability in paediatric patients.

Ozalin undergoes a sterile filtration procedure, which was determined to be the best microbial preservation method for optimizing midazolam stability during the development of the formulation [2]. The ampoules have a shelf-life of 24 months before opening [1]. After opening, the solution should be used immediately, with any remaining solution being discarded [1].

\section{How should Ozalin be used?}

Ozalin is indicated in children aged 6 months to 17 years, for moderate sedation before a therapeutic or diagnostic procedure, and as premedication before anaesthesia [1]. Importantly, Ozalin is given at a fixed dose of $0.25 \mathrm{mg} / \mathrm{kg}$ (up to maximum dose of $20 \mathrm{mg}$ ) based on the actual bodyweight of the paediatric patient and regardless of their age [1].

A single-use oral applicator is provided with each midazolam ampoule; the applicator is graduated by bodyweight, reducing the potential for errors in converting bodyweightbased doses to $\mathrm{mg} / \mathrm{mL}$ for administration [1]. Table 1 gives an overview of the use of Ozalin as approved in the EU [1]. Consult local prescribing information for further details.

\section{What are the pharmacological properties of Ozalin?}

\section{Pharmacodynamic properties}

Midazolam is a short-acting benzodiazepine, with CNSrelated pharmacological effects (e.g. sedative, anxiolytic, amnesic, hypnotic, muscle relaxant and anticonvulsant effects) that are consistent with those of other drugs in this class [1]. Benzodiazepines interact reversibly with the $\gamma$-aminobutyric acid (GABA) receptor of the benzodiazepines, which is the principal inhibitory neurotransmitter in the CNS [1].

Oral formulations of midazolam, including Ozalin, have a rapid onset and short duration of action [1, 21, 22]. For example, in a study in 12 healthy adults [22], a sedative effect was observed $\approx 30$ min after administration of a single dose of Ozalin $5 \mathrm{mg}$ and lasted for $\approx 50 \mathrm{~min}$. Maximum mean sedation levels occured $0.5-1 \mathrm{~h}$ post-administration, with complete alertness in all individuals at $4 \mathrm{~h}$ post-administration [22].

\section{Potential pharmacodynamic interactions}

As there is a risk of additive sedation and clinically significant respiratory depression when midazolam is used with other CNS depressants, concomitant use of Ozalin and such drugs should be avoided (Table 1) [1].

\section{Pharmacokinetic properties}

\section{Population pharmacokinetic model}

The population pharmacokinetic profile of Ozalin was evaluated using a complex non-linear mixed effect model that took into account plasma concentrations of both midazolam and its primary active metabolite (i.e. $\alpha$-hydroxymidazolam) [23]. The model incorporated data from single-dose studies of midazolam in a total of 49 participants, including 12 healthy adults [22] and 37 paediatric patients (5 infants aged $0.5-2$ years, 10 children aged $0.5-11$ years and 12 adolescents aged 12-17 years) [23]. Overall, the pharmacokinetic values with Ozalin were close to those reported for extemporaneous oral midazolam solutions/syrups in previous studies in paediatric patients [24, 25]. Based primarily on the population pharmacokinetic analysis [23] and the EU summary 
Table 1 Summary of the prescribing information of midazolam $0.2 \%$ oral solution (Ozalin ${ }^{\circledR}$ ) in the EU [1]

\section{What are the approved indications for Ozalin in children aged 6 months to 17 years?}

For moderate sedation before a therapeutic or diagnostic procedure

As premedication before anaesthesia

\section{How is Ozalin available and how should it be stored?}

Availability

Single-dose ampoules containing $5 \mathrm{~mL}$ of midazolam $2 \mathrm{mg} / \mathrm{mL}$ oral solution (10 mg/ampoule)

A single-use filter straw + a single-use oral applicator are provided for each ampoule

Storage

How should Ozalin be administered?

Dose (based on actual body- $\quad 0.25 \mathrm{mg} / \mathrm{kg}$ up to a maximum of $20 \mathrm{mg}$ (even in children weighing $>80 \mathrm{~kg}$ ) weight)

Timing of administration

$\approx 30$ min before the procedure or anaesthesia

Preparation of dose (immediately Using the filter straw, ampoule and oral applicator, fill the oral applicator to the graduation mark corbefore administration) responding to the weight of the child in $\mathrm{kg}$ (applicator is graduated from 3 to $40 \mathrm{~kg}$ )

Administration (oral use only)

Empty the contents of the oral applicator into the child's mouth, child should swallow the contents immediately

\section{How should Ozalin be used in high-risk patients?}

Patients with lung conditions

Chronic respiratory failure: use with caution (respiratory depression may be exacerbated)

Severe respiratory failure, an anatomical abnormality of the respiratory tract or lung disease: use is contraindicated

Patients with chronic renal failure

Patients with hepatic impairment

Use with caution (midazolam or its metabolite may accumulate)

Mild or moderate impairment: use with caution (midazolam or its metabolite may accumulate); carefully monitor vital signs and sedative effects

Severe impairment: use is contraindicated

Patients with heart failure

Use with caution (clearance of midazolam may decrease)

Patients in poor general health

Use with caution (patients have increased sensitivity to the CNS effects of benzodiazepines)

Patients with a history of alcoholism/drug addiction

Avoid use (in common with other benzodiazepines)

\section{What are the other contraindications to the use of Ozalin?}

Hypersensitivity to midazolam, other benzodiazepines or any of formulation excipients, including $\gamma$-cyclodextrin, citric acid monohydrate, sucralose, ethanol (in the orange flavour), and sodium hydroxide; myasthenia gravis; sleep apnoea syndrome

What clinically relevant pharmacokinetic drug interactions may potentially occur with midazolam?

CYP3A4 inhibitors ${ }^{\mathrm{a}} \quad$ Plasma concentrations of midazolam may increase, leading to increased sedative effects; carefully monitor vital signs and sedative effects

Exposure to midazolam may be effected for several days to several weeks after administration of a CYP3A4 inhibitor

CYP3A4 inducers ${ }^{\mathrm{b}}$

Plasma concentrations of midazolam may decrease, leading to reductions in psychomotor effects

\section{What clinically relevant pharmacodynamic drug interactions may potentially occur with midazolam?}

Alcohol (including alcoholcontaining medications)

Other sedatives, hypnotics and CNS depressants
Strictly avoid concomitant use (increases sedation and the risk of clinically significant respiratory depression)

Avoid concomitant use (increases sedation and the risk of clinically significant respiratory depression)

CYP cytochrome $\mathrm{P} 450$

${ }^{a}$ Examples include azole antifungals, macrolide antibiotics, HIV protease inhibitors, histamine $\mathrm{H}_{2}$ antagonists, fluvoxamine, verapamil, diltiazem, nefazodone, ivacaftor, atorvastatin, aprepitant, propiverine, grapefruit juice, Echinacea purpurea, turmeric rhizome

${ }^{\mathrm{b}}$ Examples include rifamycin, carbamazepine, phenytoin, efavirenz, St. John's wort

of product characteristics [1], Ozalin is associated with the following:

- Rapid absorption Following oral administration of a dose of Ozalin, $77 \%$ of midazolam was absorbed within
30 min [23], therefore, Ozalin should be given to paediatric patients $\approx 30$ min before the procedure/anaesthesia (Table 1) [1]. A second apparent midazolam peak may occur in some patients and are thought to be caused by delayed gastric emptying [22, 23]. 
- Age-dependent metabolism Midazolam undergoes first-pass metabolism by cytochrome P450 (CYP) 3A4 enzymes to the pharmacologically active primary metabolite $\alpha$-hydroxymidazolam, which account for $30-50 \%$ of the clinical effects of midazolam [1]. $\alpha$-Hydroxymidazolam is present in high concentrations $1.5-2 \mathrm{~h}$ after administration of Ozalin, with children having a higher ratio of $\alpha$-hydroxymidazolam to midazolam than adolescents and adults (metabolic ratio 0.504 vs 0.364 and 0.313 ), which may be due to infants having a lower rate of renal clearance of $\alpha$-hydroxymidazolam than of midazolam [23].

- Bodyweight-dependent central volume of distribution Bodyweight affects the volume of distribution of midazolam, but not of $\alpha$-hydroxymidazolam [23]. Midazolam is very lipophilic, extensively distributed (central and peripheral volumes of distribution estimated to be 27.9 and $413 \mathrm{~L}$ in a typical 34-kg patient) and highly (96$98 \%$ ) bound to plasma proteins (primarily albumin) [1, 23].

- Age- and bodyweight-dependent clearance Midazolam and $\alpha$-hydroxymidazolam clearance rates are lower in infants than in adults, due to age-related differences in hepatic and intestinal enzyme expression and activity [23]. Clearance of midazolam per bodyweight is higher in infants than in older individuals, due to their larger liver size normalized to bodyweight; clearance of $\alpha$-hydroxymidazolam per bodyweight is consistent across various age groups. For a typical $34-\mathrm{kg}$ patient, estimated midazolam and $\alpha$-hydroxymidazolam clearance rates are 34.7 and $40.6 \mathrm{~L} / \mathrm{h}$, respectively [23].

- Variable elimination rates $\mathrm{In}$ the literature, $\mathrm{t}_{1 / 2}$ values for midazolam vary greatly in children $(0.5-7 \mathrm{~h})$ regardless of patient age and the midazolam dose [1]. In adolescents receiving Ozalin, the estimated $t_{1 / 2}$ of midazolam was $3.6 \mathrm{~h}$ [23]. Midazolam is eliminated primarily in the urine in the form of metabolites $(<1 \%$ as unchanged drug) [1].

Importantly, as bodyweight influences exposure to midazolam in paediatric patients, the dose of Ozalin is calculated based on actual bodyweight (i.e. $0.25 \mathrm{mg} / \mathrm{kg}$ to a maximum of $20 \mathrm{mg}$ ), even in children weighing $>80 \mathrm{~kg}$ (Table 1), regardless of their age [1].

\section{Compared with other midazolam formulations}

The inclusion of $\gamma$-cyclodextrins in the Ozalin formulation of midazolam had little effect on the pharmacokinetic properties of midazolam, as shown by the results of single-dose studies in healthy adults $[22,26]$ and adolescent patients [23].

In healthy adults, Ozalin had a relative bioavailability of $39.6 \%$ and a slightly shorter terminal half-life $\left(\mathrm{t}_{1 / 2}\right)$ than intravenous midazolam (Table 2) [22]. The pharmacokinetic profile of Ozalin in adults was similar to that of the same dose of an extemporaneously prepared oral midazolam solution (Table 2), with a relative bioavailability of $97.4 \%$ (absolute bioavailability $\approx 53 \%$ for both formulations) [26]. Mean pharmacokinetic values in adolescent patients (Table 2) were broadly consistent with those in adults [23]. Inter-individual variability tended to be relatively high in all studies [22, 23, 26]; this is characteristic of orally administered midazolam and is likely due to inter-individual differences in levels of metabolic enzymes [22].

The values reported in these studies (Table 2) [22, 23, $26]$ are comparable to those reported in previous studies of oral midazolam solutions/syrups. For example, studies which included 12-20 healthy adults per treatment arm,

\section{Table 2 Summary of the pharmacokinetic profile of midazolam $0.2 \%$ oral solution (Ozalin ${ }^{\circledR}$ ) in single-dose studies [22, 23, 26]}

\begin{tabular}{|c|c|c|c|c|c|c|}
\hline \multirow[t]{2}{*}{ Single-dose treatment } & \multicolumn{3}{|l|}{ Midazolam } & \multicolumn{3}{|c|}{ Active metabolite ( $\alpha$-hydroxymidazolam) } \\
\hline & $\begin{array}{l}\text { Mean } \mathrm{C}_{\max } \\
(\mathrm{ng} / \mathrm{mL})\end{array}$ & Median $\mathrm{t}_{\max }($ range $)[\mathrm{h}]$ & Mean $t_{1 / 2}(h)$ & $\begin{array}{l}\text { Mean } C_{\text {max }} \\
(\mathrm{ng} / \mathrm{mL})\end{array}$ & Median $\mathrm{t}_{\max }$ (range) $[\mathrm{h}]$ & Mean $t_{1 / 2}(h)$ \\
\hline \multicolumn{7}{|c|}{ Ozalin vs IV midazolam $\mathrm{HCl}$ in a randomized, open-label crossover study in $\mathbf{1 2}$ healthy adults [22] } \\
\hline Ozalin $15 \mathrm{mg}$ & 113 & 0.58 & 2.7 & 57 & 0.58 & 2.3 \\
\hline IV midazolam $\mathrm{HCl} 5 \mathrm{mg}$ & 250 & 0.08 & 3.0 & 13 & 0.25 & 3.2 \\
\hline \multicolumn{7}{|c|}{ Ozalin vs an extemporaneous oral midazolam in a randomized, double-blind crossover study in 30 healthy adults [26] } \\
\hline Ozalin $0.25 \mathrm{mg} / \mathrm{kg}$ & 142 & $0.50(0.25-4.03)$ & 2.8 & 232 & $0.58(0.25-4.03)$ & 2.7 \\
\hline $\begin{array}{l}\text { Extemporaneous oral } \\
\text { midazolam } 0.25 \mathrm{mg} / \mathrm{kg}\end{array}$ & 137 & $1.00(0.25-4.03)$ & 2.9 & 221 & $1.00(0.25-4.00)$ & 2.8 \\
\hline \multicolumn{7}{|c|}{ Ozalin in an open-label study in 12 adolescent patients aged 12-17 years [23] } \\
\hline Ozalin $0.3 \mathrm{mg} / \mathrm{kg}^{\mathrm{a}}$ & 40.8 & $0.75(0.25-6.00)$ & 3.6 & 29.1 & $0.88(0.25-3.08)$ & 2.1 \\
\hline
\end{tabular}

$C_{\max }$ maximum plasma concentration, $\mathrm{HCl}$ hydrochloride, $I V$ intravenous, $t_{\max }$ time to reach $\mathrm{C}_{\max }, t_{1 / 2}$ terminal half life

${ }^{\mathrm{a}}$ Maximum $10 \mathrm{mg}$ 
the bioavailability of oral midazolam solutions/syrups was $21-35 \%$ and the $t_{1 / 2}$ was $1.4-4.7 \mathrm{~h}[21,27-30]$.

\section{Potential pharmacokinetic drug and food interactions}

Exposure to midazolam may be increased or decreased in patients receiving CYP3A4 inhibitors or inducers, respectively, potentially leading to a corresponding increase or decrease in efficacy and risk of adverse effects (Table 1) [1]. Although the potential for such drug interactions may be an issue in only a small proportion of paediatric patients, consumption of grapefruit juice, a CYP3A4 inhibitor, should also be avoided prior to the use of Ozalin [1], as it may increase exposure to midazolam [31].

\section{What is the efficacy of Ozalin in children?}

The EU approval of Ozalin for moderate sedation before a therapeutic or diagnostic procedure and as premedication before anaesthesia in children aged 6 months to 17 years was based on historical published data [1] and the efficacy results of the phase 2 study in 37 paediatric patients [32].

Historically, oral midazolam has been shown to be an effective sedative prior to medical procedures requiring sedation without anaesthesia and surgical procedures requiring anaesthesia [1]. Overall, in studies involving hundreds of paediatric patients requiring moderate sedation prior to anaesthesia/medical procedure, monotherapy with a single dose of oral midazolam $0.25-1.0 \mathrm{mg} / \mathrm{kg}$ generally provided maximum sedative effects within 30-45 min of administration [1].

\section{Open-label phase 2 trial in children}

In addition to assessing the pharmacokinetic profile of Ozalin [23], the phase 2 trial also evaluated the sedative effect of a single $0.3 \mathrm{mg} / \mathrm{kg}$ dose (maximum $10 \mathrm{mg}$ ) of Ozalin in 37 children aged $0.5-17$ years requiring premedication before anaesthesia [32, 33]. The sedative effect of Ozalin was evaluated using The Observer's Assessment of Alertness/Sedation $(\mathrm{OAA} / \mathrm{S})$ Scale [34], a sedation scale been validated in children that assesses four components (responsiveness, eyes, facial expression and speech) $[35,36]$. A composite $\mathrm{OAA} / \mathrm{S}$ Scale score of $\leq 17$ (lower scores indicate greater sedation) was considered to indicate a satisfactory sedation response. The results were compared to those of a metaanalysis of historical literature data for oral midazolam in which age was a fixed effect.

A single oral dose of Ozalin before general anaesthesia was associated with a rapid sedative effect in paediatric patients [32]. Thirty min after administration of Ozalin, 29 of $37(78.4 \%)$ of children in the total population achieved satisfactory sedation, with comparable results across all age groups [response achieved by 7 of $8(87.5 \%)$ children aged 6-23 months, 12 of 17 (70.6\%) children aged 2-11 years, and 10 of 12 (83.3\%) children aged 12-17 years] [32].

These results were consistent with the historical data for midazolam, with no significant $(p=0.94)$ differences in sedation response rates at midazolam doses of $0.2-1.5 \mathrm{mg} /$ $\mathrm{kg}$ [32]. The sedation response rate with Ozalin was consistent with that of the historical data for a similar $0.25 \mathrm{mg} / \mathrm{kg}$ dose of oral midazolam and, importantly, with that of higher oral midazolam doses of $0.5,0.75,1.0$ and $1.5 \mathrm{mg} / \mathrm{kg}$ (78 vs $\approx 80-90 \%$; values estimated from a figure) [32]. In addition, sedation response rates did not significantly differ (all $p>0.2$ ) across all midazolam doses or in various age groups. Moreover, at a dose of $0.25 \mathrm{mg} / \mathrm{kg}$, sedation response rates did not differ to a significant $(p=0.32)$ extent between the types of formulation (Ozalin, commercial midazolam syrup and hospital preparation of midazolam) [32].

Premedication with Ozalin also rapidly reduced preanaesthesia anxiety, as assessed using the Modified Yale Preoperative Anxiety Scale (mYPAS), in paediatric patients in this trial [33].

\section{What is the tolerability profile of Ozalin?}

The overall tolerability profile of midazolam is consistent with that of other benzodiazepines, with adverse effects such as drowsiness, ataxia, dysarthria and nystagmus being common [1]. Currently available data are insufficient to estimate the frequency of treatment-emergent or -related adverse events with single-dose Ozalin in paediatric patients [1]. Table 3 summarizes the disorders (listed by system organ class) that have been reported with midazolam.

\section{Effect on respiratory function}

Due to their muscle relaxant properties, midazolam and other benzodiazepines have the potential to alter respiratory function [37, 38]. In a study in 18 children aged 3-8 years with normal lung function undergoing elective surgery [39], premedication with oral midazolam $0.3 \mathrm{mg} / \mathrm{kg}$ was associated with statistically significant, but relatively mild, changes in respiratory function, ventilation homogeneity and respiratory mechanics shortly after administration. For example, relative to baseline at 20 min post-administration of midazolam, mean values for functional residual capacity, lung clearance index, respiratory resistance and respiratory elastance deteriorated by $-6.5,+7.8,+7.4$ and $+9.2 \%$, respectively (all $p<0.001$ vs baseline), with a significant correlation between these changes $(p<0.001)$ [39]. Oxygen saturation remained $\geq 95 \%$ in all patients after administration of oral midazolam [39]. 
Table 3 Adverse effects reported with midazolam (current data do not allow the frequency of the disorders to be estimated) [1]

\begin{tabular}{|c|c|}
\hline System classification & Disorders reported \\
\hline Cardiac disorders & Tachycardia, bradycardia \\
\hline Eye disorders & Blurred vision, diplopia (generally mild) \\
\hline Gastrointestinal disorders & Vomiting, nausea \\
\hline General disorders & Unusual fatigue, feeling of weakness \\
\hline Immune system disorders & Hypersensitivity, angioedema \\
\hline Muscular and connective tissue disorders & Impaired muscular control \\
\hline Nervous system disorders & $\begin{array}{l}\text { Prolonged/over sedation, drowsiness, somnolence, dizziness, ataxia, vertigo, dysarthria, dry } \\
\text { mouth, salivation, enuresis, headache, anterograde amnesia }\end{array}$ \\
\hline Psychiatric disorders & $\begin{array}{l}\text { Paradoxical reactions (agitation, excitation, hallucinations, aggressiveness, disinhibition, dys- } \\
\text { phoria, adverse behaviour, anxiety), sleep disturbances, involuntary movements, akathisia, } \\
\text { walking instability, tremors }\end{array}$ \\
\hline Respiratory, thoracic and mediastinal disorders & $\begin{array}{l}\text { Hypoxemia, transient desaturation, laryngospasm, respiratory depression, airway obstruction, } \\
\text { rhonic/noisy breathing, hiccupping, dyspnoea }\end{array}$ \\
\hline Skin and subcutaneous tissue disorders & Pruritus, urticaria reaction, skin rash \\
\hline
\end{tabular}

Although only small changes in respiratory function occurred with the use of midazolam $0.3 \mathrm{mg} / \mathrm{kg}$ in children with normal lung function, midazolam formulations, including Ozalin, should be used with caution in patients with chronic respiratory conditions (Table 1) [1]. If necessary, flumazenil can be administered to reverse the respiratory effects of midazolam [1, 40].

\section{What is the current clinical position of Ozalin?}

Paediatric patients should be assessed before undergoing sedation or anaesthesia, with a multi-disciplinary approach being used to individualize treatment and management, and identify areas requiring special precautions [4]. According to the European Society of Pediatric Anaesthesiology 2019 Clinical Practice statement [4], the drug/technique selected for paediatric procedural sedation depends on the type and length of the procedure, target level of sedation, contraindications to specific drugs, the tolerability of the option, informed child and/or caregiver preference, and the age and level of understanding of the child.

Ozalin, is a valuable option that, unlike some other commonly used sedative/pre- anaesthesia drugs, is specifically indicated to provide moderate sedation before a therapeutic or diagnostic procedure, and as premedication before anaesthesia, in children aged 6 months to 17 years. It offers benefits over extemporaneous oral solutions of midazolam, as well as over other marketed midazolam formulations. Oral midazolam formulations provide the following, with some advantages being specifically associated with Ozalin:

- Well-established efficacy with a wide margin of safety Oral midazolam has been shown to be effective and well tolerated when used to provide procedural sedation or premedication before anaesthesia in infants, children and adolescents.

- Rapid onset and short duration of action After oral administration, most of a dose of midazolam is absorbed within $\approx 30 \mathrm{~min}$, with a $\mathrm{t}_{1 / 2}$ of $\approx 2 \mathrm{~h}$.

- Uses the lowest effective midazolam dose The dose of Ozalin is $0.25 \mathrm{mg} / \mathrm{kg}$, regardless of age (maximum $20 \mathrm{mg}$ ). Clinical studies have shown that midazolam $0.25 \mathrm{mg} / \mathrm{kg}$ is effective, with this dose providing sedative effects consistent with the historical data for midazolam at the same or higher (i.e. $0.5-1.5 \mathrm{mg} / \mathrm{kg}$ ) doses.

- Little risk of clinically significant adverse events Due to the low dose of Ozalin administered, the risk of clinically relevant adverse events associated with benzodiazepine therapy, including decreased respiratory function, is low.

- Reversible effects The effects of midazolam can be reversed by administering flumazenil.

- Preferred administration route Oral administration of midazolam is preferred over invasive administration routes by many paediatric patients and their caregivers, particularly those who are 'needle-phobic'.

- Easy oral administration A single-use filter straw + a single-use oral applicator are provided for each Ozalin ampoule, making it easy to administer Ozalin without the need for other supplies. As the applicator provided is graduated by bodyweight, the potential for errors in converting bodyweight-based doses to $\mathrm{mg} / \mathrm{mL}$ is reduced.

- Enhanced palatability and acceptance The inclusion of $\gamma$-cyclodextrin in Ozalin results in the formation of $\gamma$-cyclodextrin-midazolam inclusion complexes, thereby masking the bitter taste of midazolam, as well as increasing its solubility and the stability of the solution. 
Acknowledgements The manuscript was reviewed by: H. Dupont, Pôle Anesthésie-Réanimation, CHU Amiens-Picardie, and INSERM U1088, Amiens, France; F. Marçon, Pharmacie à Usage Intérieur, CHU Amiens-Picardie, Amiens, France; N. Najafi, Department of Anaesthesiology and Perioperative Medicine, Vrije Universiteit Brussel-Universitair Ziekenhuis Brussel, Brussels, Belgium; M. Vittinghoff, Department of Anesthesiology and Intensive Care, Medical University Graz, Graz, Austria. During the peer review process, Primex Pharmaceuticals, the marketing-authorization holder of Ozalin, was also offered an opportunity to provide a scientific accuracy review of their data. Changes resulting from comments received were made on the basis of scientific and editorial merit.

\section{Compliance with ethical standards}

Funding The preparation of this review was not supported by any external funding.

Conflicts of interest K.A. Lyseng-Williamson is an employee of Adis/ Springer, is responsible for the article content and declares no conflicts of interest.

Open Access This article is distributed under the terms of the Creative Commons Attribution-NonCommercial 4.0 International License (http://creativecommons.org/licenses/by-nc/4.0/), which permits any noncommercial use, duplication, adaptation, distribution and reproduction in any medium or format, as long as you give appropriate credit to the original author(s) and the source, provide a link to the Creative Commons license and indicate if changes were made.

\section{References}

1. Ozalin $2 \mathrm{mg} / \mathrm{ml}$ oral solution: summary of product characteristics. Helsinki: Primex Pharmaceuticals OY; 2018.

2. Marçon F, Mathiron D, Pilard S, et al. Development and formulation of a $0.2 \%$ oral solution of midazolam containing $\gamma$-cyclodextrin. Int J Pharm. 2009;379(2):244-50.

3. Mason KP, Seth N. Future of paediatric sedation: towards a unified goal of improving practice. Br J Anaesth. 2019. https://doi. org/10.1016/j.bja.2019.01.025.

4. Zielinska M, Bartkowska-Sniatkowska A, Becke K, et al. Safe paediatric procedural sedation and analgesia by anaesthesiologists for elective procedures: a Clinical Practice Statement from the European Society for Pediatric Anaesthesiology. Paediatr Anaesth. 2019. https://doi.org/10.1111/pan.13615.

5. Brosius KK, Bannister CF. Oral midazolam premedication in preadolescents and adolescents. Anesth Analg. 2002;94(1):31-6.

6. Neuman G, Swed Tobia R, Koren L, et al. Single dose oral midazolam for minor emergency department procedures in children: a retrospective cohort study. J Pain Res. 2018;11:319-24.

7. Shoroghi M, Arbabi S, Farahbakhsh F, et al. Perioperative effects of oral midazolam premedication in children undergoing skin laser treatment: a double-blinded randomized placebo-controlled trial. Acta Cir Bras. 2011;26(4):303-9.

8. Sarhan MM, Aldehayat GS. Preanesthetic medication using oral midazolam in children undergoing tonsillectomy under general anesthesia. Rawal Med J. 2011;36(4):237-68.

9. Sheta SA, Alsarheed M. Oral midazolam premedication for children undergoing general anaesthesia for dental care. Int J Pediatr. 2009;2009:274380.
10. Khodadad A, Aflatoonian M, Jalilian R, et al. Comparison of oral midazolam with intravenous midazolam for sedation children during upper gastrointestinal endoscopy. Acta Med Iran. 2016;54(9):576-82.

11. Rafeey M, Ghojazadeh M. Oral midazolam in pediatric upper gastrointestinal endoscopy. J Gastroenterol Hepatol. 2012;5:104.

12. Aydintug YS, Okcu KM, Guner Y, et al. Evaluation of oral or rectal midazolam as conscious sedation for pediatric patients in oral surgery. Mil Med. 2004;169(4):270-3.

13. Deshmukh PV, Kulkarni SS, Parchandekar MK, et al. Comparison of preanesthetic sedation in pediatric patients with oral and intranasal midazolam. J Anaesth Clin Pharmacol. 2016;32(3):353-8.

14. Manoj M, Satya Prakash MVS, Swaminathan S, et al. Comparison of ease of administration of intranasal midazolam spray and oral midazolam syrup by parents as premedication to children undergoing elective surgery. J Anesth. 2017;31(3):351-7.

15. Gregory DF, Koestner JA, Tobias JD. Stability of midazolam prepared for oral administration. South Med J. 1993;86(7):771-772, 6.

16. Steedman SL, Koonce JR, Wynn JE, et al. Stability of midazolam hydrochloride in a flavored, dye-free oral solution. Am J Hosp Pharm. 1992;49(3):615-98.

17. Isik B, Baygin $\mathrm{O}$, Bodur $\mathrm{H}$. Effect of drinks that are added as flavoring in oral midazolam premedication on sedation success. Paediatr Anaesth. 2008;18(6):494-500.

18. Loftsson T, Gudmundsdóttir H, Sigurjónsdóttir JF, et al. Cyclodextrin solubilization of benzodiazepines: formulation of midazolam nasal spray. Int J Pharm. 2001;212:29-40.

19. Jansook P, Ogawa N, Loftsson T. Cyclodextrins: structure, physicochemical properties and pharmaceutical applications. Int $\mathbf{J}$ Pharm. 2018;535(1-2):272-84.

20. Mathiron D, Marcon F, Dubaele JM, et al. Benefits of methylated cyclodextrins in the development of midazolam pharmaceutical formulations. J Pharm Sci. 2013;102(7):2102-11.

21. Smith MT, Eadie MJ, Brophy TO. The pharmacokinetics of midazolam in man. Eur J Clin Pharmacol. 1981;19(4):271-8.

22. Guittet C, Manso M, Burton I, et al. A two-way randomized cross-over pharmacokinetic and pharmacodynamic study of an innovative oral solution of midazolam (ADV6209). Pharm Res. 2017;34(9):1840-8

23. Marçon F, Guittet C, Manso MA, et al. Population pharmacokinetic evaluation of ADV6209, an innovative oral solution of midazolam containing cyclodextrin. Eur J Pharm Sci. 2018;114:46-54.

24. Payne K, Mattheyse FJ, Liebenberg D, et al. The pharmacokinetics of midazolam in paediatric patients. Eur J Clin Pharmacol. 1989;37(3):267-72.

25. Reed MD, Rodarte A, Blumer JL, et al. The single-dose pharmacokinetics of midazolam and its primary metabolite in pediatric patients after oral and intravenous administration. J Clin Pharmacol. 2001;41(12):1359-69.

26. Guittet C, Manso M, Granier LA. A phase I randomized two-way cross-over study comparing the pharmacokinetic profile and relative bioavailability of ADV6209 versus an extemporane oral midazolam formulation in healthy subjects [abstract no. $63+$ poster]. In: European Society for Paediatric Anaesthesiology (ESPA) and Internationsl Assembly for Pediatric Anesthesis (IAPA) Congress. 2018.

27. Brill MJ, van Rongen A, Houwink AP, et al. Midazolam pharmacokinetics in morbidly obese patients following semi-simultaneous oral and intravenous administration: a comparison with healthy volunteers. Clin Pharmacokinet. 2014;53(10):931-41.

28. Hohmann N, Kocheise F, Carls A, et al. Midazolam microdose to determine systemic and pre-systemic metabolic CYP3A activity in humans. Br J Clin Pharmacol. 2015;79(2):278-85.

29. Lee JI, Chaves-Gnecco D, Amico JA, et al. Application of semisimultaneous midazolam administration for hepatic and 
intestinal cytochrome P450 3A phenotyping. Clin Pharmacol Ther. 2002;72(6):718-28.

30. Tateishi T, Watanabe M, Nakura HY, et al. CYP3A activity in European American and Japanese men using midazolam as an in vivo probe. Clin Pharmacol Ther. 2001;69(5):333-9.

31. Goho C. Oral midazolam-grapefruit juice drug interaction. Pediatr Dent. 2001;23(4):365-6.

32. Guittet C, Manso M, Casagrande L, et al. Evaluation of the efficacy of an innovative oral formulation of midazolam for moderate sedation in pediatric patients [abstract no. PR240]. Anesth Analg. 2016;123 (3 Suppl 2):313-4.

33. Marçon F, Legrand A, Guittet C, et al. Phase II clinical study of a pediatric oral solution of midazolam $0.2 \%\left(\right.$ Ozaline $\left.^{\circledR}\right)$ for anesthetic premedication [in French] [abstract no. R196]. In: Société Française d'Anesthésie et de Réanimation (SFAR). 2015.

34. Chernik DA, Gillings D, Laine H, et al. Validity and reliability of the Observer's Assessment of Alertness/Sedation Scale: study with intravenous midazolam. J Clin Psychopharmacol. 1990;10(4):244-51.

35. Sadhasivam S, Ganesh A, Robison A, et al. Validation of the bispectral index monitor for measuring the depth of sedation in children. Anesth Analg. 2006;102:383-8.
36. Malviya S, Voepel-Lewis T, Tait AR, et al. Depth of sedation in children undergoing computed tomography: validity and reliability of the University of Michigan Sedation Scale (UMSS). Br J Anaesth. 2002;88:241-5.

37. Gonzalez Castro LN, Mehta JH, Brayanov JB, et al. Quantification of respiratory depression during pre-operative administration of midazolam using a non-invasive respiratory volume monitor. PLoS One. 2017;12(2):e0172750. https://doi.org/10.1371/journ al.pone. 0172750 .

38. Prato FD, Knill RL. Diazepam sedation reduction functional residual capacity and alters the distribution of ventilation in man. Can Anaesth Soc J. 1983;30:493-500.

39. von Ungern-Sternberg BS, Erb TO, Habre W, et al. The impact of oral premedication with midazolam on respiratory function in children. Anesth Analg. 2009;108(6):1771-6.

40. Araki H, Fujiwara Y, Shimada Y. Effect of flumazenil on recovery from sevoflurane anesthesia in children premedicated with oral midazolam before undergoing herniorrhaphy with or without caudal analgesia. J Anesth. 2005;19(3):204-7. 